\title{
ANALIZE NEKIH MORFOLOŠKIH SVOJSTAVA ASIMILACIONOG APARATA JELE (Abies alba Mill.) U EKSPERIMENTU „DELIMUSA“
}

Morphological analysis of some assimilation characteristics of the silver fir (Abies alba Mill.) in the experiment "Delimusa"

\author{
Velid Halilović $^{1}$, Dalibor Ballian ${ }^{1}$, Faruk Mekić ${ }^{1}$, Ćemal Višnjić ${ }^{1}$
}

\begin{abstract}
On the "Delimusa" section 86, economic units "Krivaja" on ŠPP "Olovsko", was built experimental plane ordinary fir with nine provenience. We analyzed the number of needle-per-cm by provenience, the dimensions of the needle by provenience needle and participation by age. For all the properties variance analysis, as in Duncanov test showed statistically significant differences between studied provenience.

The results we obtained can be used for differentiation silver fir, or to estimate the population variability.
\end{abstract}

$\underline{\text { Key words: }}$ silver fir (Abies alba Mill.) variability, needles

\section{Izvod}

Na lokalitetu „Delimusa“, odjel 86, gospodarska jedinica „Krivaja“ na ŠPP „Olovsko“, podignuta je eksperimentalna ploha jele sa devet provenijencija.

U svakoj provenijenciji analizirali smo broj iglica po $\mathrm{cm}$ dužnom, njihovu dužinu, širinu i učešće prema starosti. Za sva svojstva analiza varijanse, kao i Duncanov test su pokazali statistički značajne razlike između istraživanih provenijencija.

Dobiveni rezultati mogu poslužiti za diferencijaciju jele, odnosno za procjenu međupopulacijske varijabilnosti.

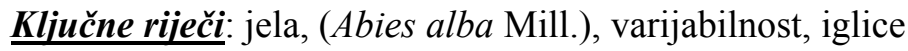

${ }^{1}$ Šumarski fakultet Univerziteta u Sarajevu - Faculty of Forestry University of Sarajevo 


\section{Uvod - Introduction}

Jela (Abies alba Mill.) je jedna od najznačajnijih vrsta šumskog drveća s gospodarskog i ekološkog stanovišta u Bosni i Hercegovini (FUKAREK, 1970; STEFANOVIĆ et al., 1983; UsČUPLIĆ, 1992; BALLIAN I ČABARAVDIĆ, 2005).

Glavno područje rasprostiranja jele u Bosni i Hercegovini je duž dinarskih planina, u više odvojenih, većih i manjih područja (FUKAREK, 1970; STEFANOVIĆ et al., 1983). Ukupna površina visokih šuma gdje raste jela iznosi 562.237 ha ili oko $50 \%$ svih visokih šuma Bosne i Hercegovine. Ukupna masa drvne zalihe jele u šumama iznosi $63.923 .000 \mathrm{~m}^{3}$, što je oko $23 \%$ ukupne drvne zalihe unutar svih visokih šuma, pa je i takvo učešće jelovog drveta u drvoprerađivačkim pogonima (UščUPLIĆ, 1992).

Nažalost, zdravstveno stanje šuma jele nije dobro i ima tendenciju stalnog pogoršavanja. Za razliku od jelovih šuma u Srednjoj Europi gdje jela propada usljed štetnog djelovanja stalnog onečišćenja atmosfere i tla, u BiH se stanje pogoršava često i zbog slabog sistema gospodarenja. Slab i nepostojan sistem gazdovanja dovodi do narušavanja stabilnosti jelovih šuma, što za izravnu posljedicu ima pojavu imele (Viscum album var. abietis Beck.). To kasnije dovodi i do pojave drugih patogena (UsČUPLIĆ, 1992; UsČUPLIĆ et al., 2007).

Potreba izdvajanja i kontrolisanja različitih provenijencija jele je diktirana pojavom njene prirodne varijabilnosti, koja je uzrokovana (najčešće) klimatskim i edafskim faktorima. S druge strane, prilagođavanje šumskog drveća specifičnim uslovima različitih staništa u Bosni i Hercegovini dovelo je do stvaranja posebnih klimatskih ili lokalnih rasa kod svih vrsta drveća, među koje svakako spada i jela. To se najčešće manifestuje $u$ izvjesnim biološkim i morfološkim osobinama, te $u$ ekološkim zahtjevima, o čemu se prilikom provođenja uzgojnih radova treba voditi računa.

U cilju povećanja proizvodnosti šuma u $\mathrm{BiH}$ već početkom pedesetih godina prošlog stoljeća započeto je i odabiranje najboljih sjemenskih sastojina jele unutar šumskih kompleksa (Đikı́ et al., 1965). Posao nije priveden kraju, te se njemu ponovo pristupa 1982. Godine, da bi 1986. godine bio napravljen elaborat na temu: Revizija postojećih $i$ izdvajanje novih sjemenskih sastojina $i$ proučavanje bioloških karakteristika smrče, jele, bijelog $i$ crnog bora u funkciji proizvodnje kvalitetnog sjemena za potrebe šumarstva SR BiH.

U sklopu istraživanja izvršen je izbor najboljih sastojina jele. Njihovim uređenjem bi se formirala solidna baza za vegetativnu i generativnu reprodukciju, a potomstvu omogućio brz rast, dobar oblik, dobra tehnološka svojstva i otpornost na biotske i abiotske faktore.

Osnovna provjera navedenih pretpostavki trebala je da se izvrši preko eksperimentalne rejonizacije podizanjem provenijencijskih ogleda, o čemu postoje brojni rezultati u zemlji i svijetu (BECKER, 1971; BRINAR, 1976; MEKIĆ, 1988; KRAMER i StePHAN, 1992; COMMARMOT, 1992; RUetZ et al., 1998). 
Ogled sa jelom iz devet različitih provenijencija podignut na širem području Olova, odnosno lokalitetu „Delimusa“, odjel 86, gospodarska jedinica „Krivaja“ na ŠPP „Olovsko“, predmet je ovog istraživanja.

Preko ovog provenijencijskog ogleda sa jelom i testiranja njenih populacija želi se dobiti odgovor na neka od pitanja koja su vezana za varijabilnost njenih određenih morfoloških karakteristika i njihov značaj za proizvodno šumarstvo.

Cilj ovog istraživanja je da se suvremenim statističkim metodama, uz primjenu multifaktorijalne analize, utvrdi međupopulacijska varijabilnost broja, dužine, širine i procentualnog učešća iglica po godinama starosti pojedinih populacija.

\section{Materijal i metode istraživanja - Materials and Methods}

Sjeme za podizanje ogleda sa jelom potiče sa područja Bugojna, Bos. Petrovca, Olova (Palež), Pala, Konjica, Fojnice, Sokoca, Olova - Klis i Prozora, sa nadmorskih visina od 850 do $1300 \mathrm{~m}$ (tabela 1 ).

Tabela 1. Osnovni podaci o provenijencijama jele

Table 1. Basic data on a regular provenience silver fir.

\begin{tabular}{|l|l|l|r|c|c|}
\hline $\begin{array}{c}\text { Provenijencija } \\
\text { Provenince }\end{array}$ & \multicolumn{1}{|c|}{$\begin{array}{c}\text { Tip zemljišta } \\
\text { The type of land }\end{array}$} & $\begin{array}{l}\text { Geološka podloga } \\
\text { Geology basis }\end{array}$ & $\begin{array}{c}\text { Nadmorska } \\
\text { visina } \\
\text { Altitude } \\
\text { (m) }\end{array}$ & $\begin{array}{l}\text { Ekspozicija } \\
\text { Exposure }\end{array}$ & $\begin{array}{c}\text { Nagib } \\
\text { terena } \\
\text { Slope } \\
\text { (\%) }\end{array}$ \\
\hline 1. Bugojno & $\begin{array}{l}\text { rendzina, } \\
\text { kalkokambisol }\end{array}$ & $\begin{array}{l}\text { dolomit i } \\
\text { krečnjak }\end{array}$ & 1.090 & $\mathrm{~N}-\mathrm{W}$ & $10-25$ \\
\hline 2. Petrovac & $\begin{array}{l}\text { rendzina, } \\
\text { kalkokambisol }\end{array}$ & dolomit & 900 & $\mathrm{~N}$ & 2 \\
\hline $\begin{array}{l}\text { 3. Olovo- } \\
\text { Palež }\end{array}$ & $\begin{array}{l}\text { kalkokambisol, } \\
\text { luvisol }\end{array}$ & krečnjak & 960 & $\mathrm{~N}-\mathrm{E}$ & 12 \\
\hline 4. Pale & $\begin{array}{l}\text { distrični kambis., } \\
\text { kalkomelanosol }\end{array}$ & $\begin{array}{l}\text { verfenski škriljci, } \\
\text { pješčari, krečnjak }\end{array}$ & 1.200 & $\mathrm{~N}-\mathrm{E}$ & 20 \\
\hline 5. Konjic & $\begin{array}{l}\text { kalkokambisol, } \\
\text { kalkomelanosol }\end{array}$ & jedri krečnjaci & 1.030 & $\mathrm{E}-\mathrm{EN}$ & $10-22$ \\
\hline 6. Fojnica & $\begin{array}{l}\text { distrični } \\
\text { kambisol }\end{array}$ & riolit & 1.010 & $\mathrm{~N}-\mathrm{E}$ & 25 \\
\hline 7. Sokolac & $\begin{array}{l}\text { kalkokambisol, } \\
\text { kalkomelanosol }\end{array}$ & krečnjak & 940 & $\mathrm{~S}-\mathrm{W}$ & 13 \\
\hline $\begin{array}{l}\text { 8. Olovo - } \\
\text { Klis }\end{array}$ & $\begin{array}{l}\text { kalkokambisol, } \\
\text { luvisol }\end{array}$ & krečnjak & 850 & $\mathrm{~N}-\mathrm{W}$ & 13 \\
\hline 9. Prozor & $\begin{array}{l}\text { kalkomelanosol, } \\
\text { luvisol }\end{array}$ & $\begin{array}{l}\text { krečnjačka } \\
\text { morena }\end{array}$ & 1.300 & $\mathrm{~N}-\mathrm{E}$ & $5-10$ \\
\hline
\end{tabular}

Sadni materijal za eksperiment je proizveden u rasadniku Zavidovići, u proljeće 1991. godine, starosti 3+2. Na lokalitetu „Delimusa“ je, na već prethodno pripremljenoj površini, izvršena klasična sadnja u rupe. 
Nadmorska visina eksperimentalne površine na kojoj je podignut ogled je 970 $\mathrm{m}$, ekspozicija terena je sjeverna. Inklinacija terena se kreće u intervalu $10-20$ stepeni.

Veličina eksperimentalne površine na kojoj je izvršena sadnja je 173 m x 88 m $=1,522$ ha sa dva reda sadnica kao zaštitnim pojasom.

\begin{tabular}{|l|l|l|l|l|l|l|l|l|l|}
\hline Bugojno & $\begin{array}{l}\text { Olovo- } \\
\text { Klis }\end{array}$ & $\begin{array}{l}\text { Olovo- } \\
\text { Palež }\end{array}$ & Fojnica & Prozor & $\begin{array}{l}\text { Bos. } \\
\text { Petrovac }\end{array}$ & Sokolac & Pale & Konjic & Kontrola \\
\hline $\begin{array}{l}\text { Bos. } \\
\text { Petrovac }\end{array}$ & Sokolac & Pale & Konjic & Kontrola & Bugojno & $\begin{array}{l}\text { Olovo- } \\
\text { Klis }\end{array}$ & $\begin{array}{l}\text { Olovo- } \\
\text { Palež }\end{array}$ & Fojnica & Prozor \\
\hline Kontrola & Bugojno & $\begin{array}{l}\text { Olovo- } \\
\text { Klis }\end{array}$ & $\begin{array}{l}\text { Olovo- } \\
\text { Palež }\end{array}$ & Fojnica & Prozor & Konjic & Sokolac & Pale & $\begin{array}{l}\text { Bos. } \\
\text { Petrovac }\end{array}$ \\
\hline Fojnica & Prozor & $\begin{array}{l}\text { Bos. } \\
\text { Petrovac }\end{array}$ & Sokolac & Konjic & Pale & Kontrola & Bugojno & $\begin{array}{l}\text { Olovo- } \\
\text { Klis }\end{array}$ & $\begin{array}{l}\text { Olovo- } \\
\text { Palež }\end{array}$ \\
\hline Pale & Konjic & Kontrola & Bugojno & $\begin{array}{l}\text { Olovo- } \\
\text { Klis }\end{array}$ & $\begin{array}{l}\text { Olovo- } \\
\text { Palež }\end{array}$ & Fojnica & $\begin{array}{l}\text { Bos. } \\
\text { Petrovac }\end{array}$ & Prozor & Sokolac \\
\hline
\end{tabular}

Slika 1. Shema eksperimentalne površine

Figure 1. The scheme experimental areas

Sadnja biljaka devet provenijencija je obavljena u pet ponavljanja (blokova) prema sistematskom rasporedu (slika 1). Svaka ploha u bloku je dimenzija 14 x 14, a između ploha je odstojanje od $3 \mathrm{~m}$. Sama sadnja je obavljena na razmaku 2 x $2 \mathrm{~m}$.

Prikupljanje podataka je vršeno u toku 2005. godine i to u jesenjem periodu, pa je i starost ispitivanog materijala u tom periodu iznosila 20 godina. Sakupljani su slijedeći podaci:

- Sa deset najviših stabala u svakoj parceli unutar provenijencije uzeli smo uzorak prirasle grančice (ljetorast) dužine $10 \mathrm{~cm}$. Uzorak je uzet sa jedne od grana koje se nalaze na pršljenu, a odgovara 2003. godini, i korišten je za određivanje broja iglica po $1 \mathrm{~cm}$ dužnom.

- Nakon što smo odredili broj iglica po $\mathrm{cm}$ dužnom, isti materijal nam je poslužio i za mjerenje dužine i širine iglica. Sa svake grančice smo bez biranja uzeli uzorak od deset iglica i mjerili dužinu i širinu iglice. Za jednu provenijenciju unutar pet blokova imali smo 500 mjerenja dužina i 500 mjerenja širina iglica, odnosno ukupan broj mjerenja za sve provenijencije je izvršen na 4500 iglica.

- Na svakom stablu predstavniku po provenijencijama izvršili smo i mehaničko odvajanje asimilacionog aparata po godinama starosti, zatim sušili na $105^{\circ} \mathrm{C} \mathrm{u}$ termostatu do konstantne težine i na kraju njihovu masu vagali analitičkom vagom što je poslužilo za izračunavanje procentualnog učešća asimilacionog aparata po godinama starosti. 


\section{Rezultati istraživanja - The research results}

\section{Analiza broja iglica po cm dužnom unutar provenijencija}

U tabeli 2 smo predstavili rezultate do kojih smo došli nakon provedene analize. Najmanji broj iglica je imala provenijencija Fojnica 14,52, a najveći broj iglica je imala provenijencija Konjic 16,48.

Analizom varijanse smo utvrdili postojanje statistički značajnih razlika između provenijencija. Varijabilnost je potvrđena i formiranjem dvije grupe kod Duncan testa. Na osnovu analiza možemo konstatovati da se provenijencija Konjic statistički značajno razlikuje od svih ostalih provenijencija, osim u odnosu na provenijencije Olovo-Klis, B. Petrovac i Prozor koje imaju prosječan broj iglica.

Tabela 2. Analiza broja iglica

Table 2. Analysis of the number of needle

\begin{tabular}{|c|c|c|c|c|}
\hline \multirow{3}{*}{ R.br. } & \multirow{3}{*}{ Provenijencija } & \multicolumn{3}{|c|}{$\begin{array}{l}\text { Aritmetička sredina } \pm \text { linearna } \\
\text { odstupanja }\end{array}$} \\
\hline & & $\begin{array}{l}\text { Broj iglica } \\
\text { po } 1 \mathrm{~cm}^{\prime}\end{array}$ & $\begin{array}{l}\text { Duncan- } \\
\text { test }\end{array}$ & $\begin{array}{l}\mathrm{VK} \\
\%\end{array}$ \\
\hline & & \multicolumn{3}{|c|}{ kom } \\
\hline 1. & Fojnica & $14,52 \pm 2,029$ & & 14 \\
\hline 2. & Pale & $14,62 \pm 1,818$ & & 12 \\
\hline 3. & Olovo-Palež & $14,75 \pm 2,052$ & & 14 \\
\hline 4. & Bugojno & $14,76 \pm 2,241$ & & 15 \\
\hline 5. & Sokolac & $14,95 \pm 2,442$ & & 16 \\
\hline 6. & Olovo-Klis & $15,21 \pm 2,270$ & & 15 \\
\hline 7. & B. Petrovac & $15,73 \pm 2,379$ & & 15 \\
\hline 8. & Prozor & $15,76 \pm 1,919$ & & 12 \\
\hline 9. & Konjic & $16,48 \pm 2,031$ & & 12 \\
\hline \multicolumn{2}{|c|}{ F - vrijednost } & $4,79^{* * *}$ & & \\
\hline \multicolumn{2}{|c|}{ Srednja vr. } & $15,20 \pm 2,13$ & & 14 \\
\hline
\end{tabular}

$* * *=$ statistički visoko značajne razlike $(p \leq 0.001)$

\section{Analiza dužine i širine iglica po provenijencijama}

Nakon izvršenih mjerenja analizirali smo varijanse po navedenim provenijencijama (tabela 3). Iz tabele možemo vidjeti da i za dužinu i širinu iglica postoji statistički značajna razlika između istraživanih provenijencija. Za dužinu iglica formirane su četiri Duncan-grupe. Najmanju dužinu iglica u odnosu na sve ostale provenijencije imala je provenijencija Prozor. Najveću vrijednost dužine iglica su imale provenijencije Sokolac, Konjic i Fojnica, gdje se vrijednosti ovih provenijencija 
statistički znatno razlikuju u odnosu na provenijencije Olovo-Palež, Olovo-Klis, B. Petrovac i Prozor.

Također možemo izdvojiti grupu provenijencija Olovo-Palež, Bugojno i Pale čije vrijednosti su manje i statistički se razlikuju od dužine iglica provenijencija koje imaju najveće vrijednosti, a pokazuju veće vrijednosti u odnosu na provenijencije Olovo-Klis, B. Petrovac i Prozor i od njih se signifikantno razlikuju.

Analiza širina iglica je pokazala također veliku različitost po provenijencijama. Provenijencije Fojnica i Pale imaju najveće vrijednosti ovog istraživanog elementa i statistički se razlikuju od svih ostalih provenijencija. Najmanju vrijednost ima provenijencija Sokolac. Između ove dvije krajnje vrijednosti formirane su još dvije grupe gdje možemo izdvojiti provenijenciju Prozor, koja se razlikuje u odnosu na provenijencije Olovo-Palež i Konjic, dok ostale provenijencije pokazuju srednje vrijednosti.

Iz ovih analiza primjećuje se da je provenijencija Fojnica imala najveće vrijednosti kada je u pitanju dužina, dok je najšire iglice imala provenijencija Pale, a zatim provenijencija Fojnica.

Tabela 3. Analiza dužine i širine iglica po provenijencijama

Table 3. Analysis of the length and width of needles by Provenance

\begin{tabular}{|c|c|c|c|c|c|c|c|c|}
\hline \multirow{3}{*}{ R.br. } & \multirow{3}{*}{ Provenijencija } & \multicolumn{7}{|c|}{ Aritmetička sredina \pm linearna odstupanja } \\
\hline & & $\begin{array}{l}\text { Dužina } \\
\text { iglica }\end{array}$ & $\begin{array}{l}\text { Duncan- } \\
\text { test }\end{array}$ & $\begin{array}{l}\text { VK } \\
\%\end{array}$ & & $\begin{array}{l}\text { Širina } \\
\text { Iglica }\end{array}$ & $\begin{array}{l}\text { Duncan- } \\
\text { test }\end{array}$ & $\begin{array}{l}\text { VK } \\
\%\end{array}$ \\
\hline & & \multicolumn{7}{|c|}{$\mathrm{mm}$} \\
\hline 1. & Prozor & $17,31 \pm 3,108$ & \multirow{9}{*}{$\mid$} & 18 & Sokolac & $1,89 \pm 0,147$ & & 8 \\
\hline 2. & B. Petrovac & $17,97 \pm 2,986$ & & 17 & Olovo-Palež & $1,92 \pm 0,142$ & & 7 \\
\hline 3. & Olovo-Klis & $17,99 \pm 2,923$ & & 16 & Konjic & $1,92 \pm 0,124$ & & 6 \\
\hline 4. & Olovo-Palež & $18,02 \pm 3,016$ & & 17 & Bugojno & $1,94 \pm 0,148$ & & 8 \\
\hline 5. & Bugojno & $18,61 \pm 2,593$ & & 14 & B. Petrovac & $1,94 \pm 0,155$ & & 8 \\
\hline 6. & Pale & $18,66 \pm 3,193$ & & 17 & Olovo-Klis & $1,95 \pm 0,147$ & & 7 \\
\hline 7. & Sokolac & $18,76 \pm 3,225$ & & 17 & Prozor & $1,96 \pm 0,147$ & & 7 \\
\hline 8. & Konjic & $18,93 \pm 3,367$ & & 18 & Fojnica & $1,97 \pm 0,173$ & & 9 \\
\hline 9. & Fojnica & $19,15 \pm 2,623$ & & 18 & Pale & $1,99 \pm 0,141$ & & 7 \\
\hline \multicolumn{2}{|c|}{$\mathrm{F}$ - vrijednost } & $19,11 * * *$ & & & & $20,76^{* * *}$ & & \\
\hline \multicolumn{2}{|c|}{ Srednja vr. } & $18,38 \pm 3,0$ & & 17 & & $1,94 \pm 0,14$ & & 7 \\
\hline
\end{tabular}

$* * *=$ statistički visoko značajne razlike $(p \leq 0.001)$

\section{Učešće iglica prema starosti}

Pokazatelj koji ima odlučujuću ulogu u produkcionoj sposobnosti biljaka su proizvodni zeleni dijelovi, listovi i zeleni izbojci. Ta sposobnost proizvodnosti izravno ovisi u mnogome od starosti zelene mase (MEKIĆ, 1991).

$\mathrm{Na}$ stablima koja smo analizirali na kraju vegetacijskog perioda 2005. godine, dakle starih 20 godina, konstatovali smo da su poneka imala iglice stare do 8 godina.

Iz grafičke predstave (grafikon 1), možemo konstatovati da sa starošću iglica opada njihovo učešće na stablu, zatim da su najveća učešća najstarijih iglica $(5,6,7 \mathrm{i}$ 
8 godina starosti) imale provenijencije Fojnica i Bos. Petrovac, a najmanje Bugojno i Pale.

Nakon ovog perioda dolazi do promjene učešća iglica po godinama starosti tako što procentualno najmanje učešće najmlađih iglica $(1,2$, i 3 godine starosti), imaju provenijencije Bos. Petrovac i Fojnica, dok najveće učešće najmlađih iglica imaju provenijencije Bugojno, Pale i Sokolac.

Za razliku od nabrojanih provenijencija, ostale istraživane provenijencije pokazuju srednje vrijednosti za analizirano obilježje.

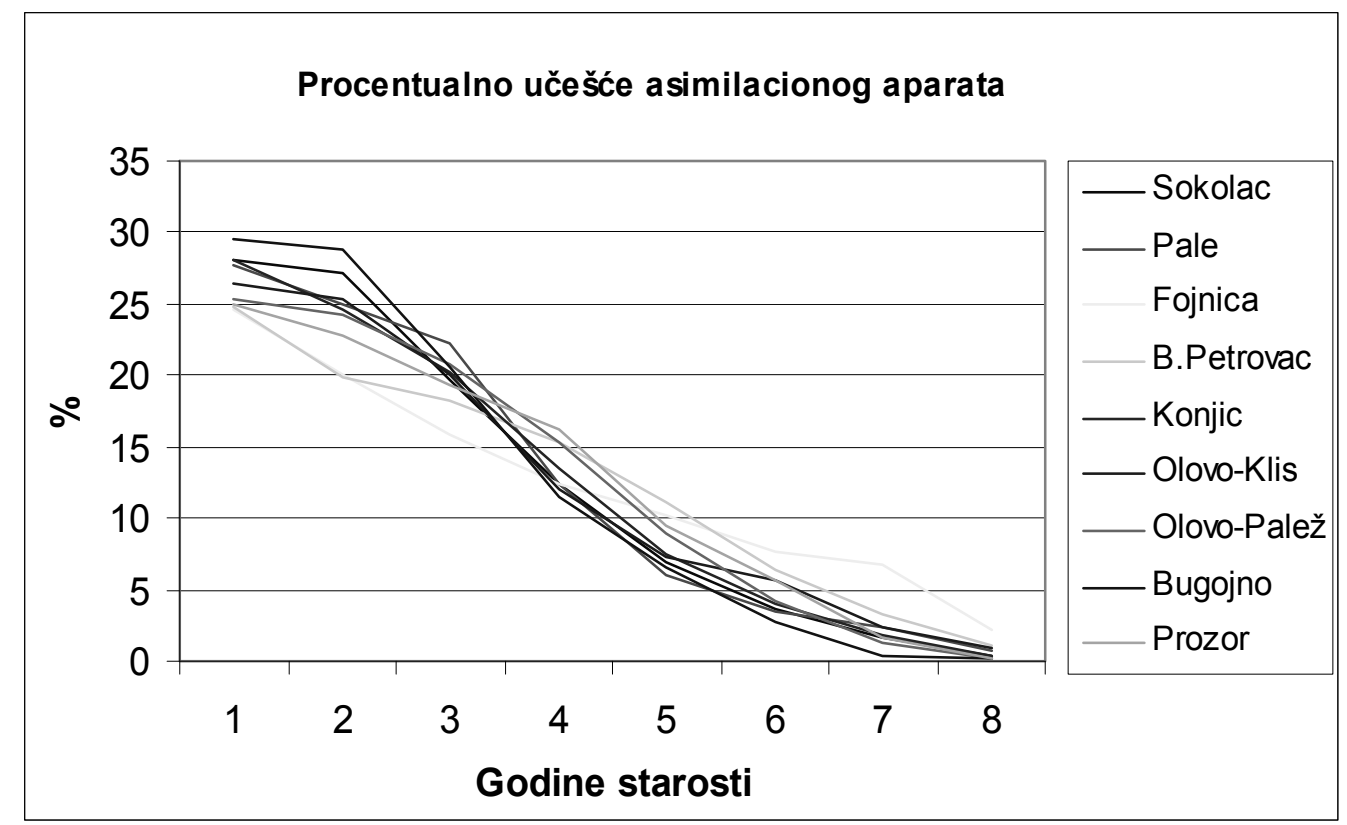

Grafikon 1. Procentualno učešće asimilacionog aparata

Graph 1. Percentage participation asimilation apparatus

\section{Diskusija-Discussion}

Istraživanja koja su provedena u Europi na različitim provenijencijama obuhvativši gotovo cijeli prirodni areal jele (Abies alba Mill.), pokazala su da u istoj starosti biljaka između provenijencija postoje velike morfološke razlike (BECKER, 1971; BRINAR, 1976; LARSEN, 1986; MEKIĆ, 1988; KRAMER i STEPHAN, 1992; COMMARMOT 1992; RUETZ i sur., 1998).

Pošto se ovdje radi o jednom segmentu prirodnog areala, koji u cijelosti ne predstavlja njegov veliki dio, bilo je za očekivati i manju varijabilnost, tim više što je ogled realiziran u ranoj fazi, gdje nasljedne osobine nisu u značajnoj mjeri izražene. Ovdje ipak prije svega do izražaja dolazi specifčnost Dinarskih planima, gdje na 
malom prostoru imamo velike razlike u uvjetima okoline, a koje izravno djeluju na diferenciranost populacija (BALLIAN, 2003 a i b).

Istraživanja anatomsko-morfološke građe iglica, kako navodi KAJBA (2001), imaju veliko značenje pri ekološko-fiziološkim i evolucijskim izučavanjima te pri selekciji pojedinih vrsta drveća.

Utvrđeno je da su iglice jele vrlo osjetljive i da brzo reagiraju na ekološke uvjete sredine, te da donekle određuju tok prirasta i razvoja drugih organa KAJBA (2001), po navodima PRAVDina (1964), MAMAEVA i RoždESTVENSKOg (1969).

POPNIKOLA (1974) je istraživao varijabilnost iglica jele na osam lokaliteta u Makedoniji i utvrdio da su najduže i najšire iglice u najnižim predjelima, dok se sa povećanjem nadmorske visine te veličine smanjuju.

Podaci koje iznosi KAJBA (2001), osvrćući se na navode Gagova (1972) za dužinu i širinu iglica obrnuti su od Popnikolinih istraživanja. On je zaključio da dimenzije pokrovnih i mehaničkih dijelova tkiva iglica variraju s obzirom na mjesto sakupljanja. S nadmorskom visinom povećava se debljina kutikule, što nije slučaj kod hipoderme i mehaničkog tkiva iglica. Asimilacijski dijelovi pokazuju znatnu varijabilnost među istraživanim lokacijama.

U ovom istraživanju smo izvršili analize širina i dužina iglica i nismo utvrdili postojanje veze između ovih parametara i nadmorske visine. Međutim, značajno je napomenuti da je provenijencija Fojnica imala najveće vrijednosti kada je u pitanju dužina iglica, dok je sa širinom iglica zaostajala za provenijencijom Pale.

Istraživanja dužine $\mathrm{i}$ širine asimilacionog aparata kod jele $\mathrm{s}$ obzirom na različite doze prihranjivanja sadnica pokazala su da je srednja doza NPK kompleksa i uree najpovoljnije djelovala na dužinu i širinu četina, a najveća doza je utjecala na smanjenje dužine i širine četina (MILANOVIĆ et al., 1980).

Jela, kao i neki drugi četinari, u toku života na sebi zadrži četine i više godina (do 8), tako da će istraživanje ovog parametra dati uvid o homogenosti bosanskohercegovačke jele (MEKIĆ, 1991) na temelju ovog svojstva.

Geografsku varijabilnost jele u Evropi s obzirom na njenu transpiraciju i oblik iglica u odnosu na njihovu dob te udio suhe tvari i njene gustoće, utvrđivali su LARSEN i MEKIĆ (1991) kod 15 provenijencija u dobi od 6 godina. Na širem području Europe uočili su diferenciranost između provenijencija.

Procentualno učešće najstarijih iglica smo konstatovali kod provenijencija Fojnica i Bosanski Petrovac, dok su provenijencije Pale i Bugojno imale procentualno najmanje učešće ovih iglica, da bi sa učešćem najmlađih iglica taj odnos bio promijenjen.

Za razliku od ovih istraživanja, svakako je vrlo bitno uporedo pratiti i genetička istraživanja koja zajedno daju dobru sliku o ekološko-fiziološkim osobitostima jele u BiH.

Potrebno je nastaviti istraživanja na ovim populacijama jele $\mathrm{u} \mathrm{BiH}$ i neprestano pratiti gospodarske zahvate na obnovi obične jele te ih usmjeravati na 
održanje genetičke raznolikosti lokalnih populacija, kao i sva druga opažanja na terenu radi donošenja suda o uniformnosti jele u uvjetima Srednje Evrope.

\section{Zaključci - Conclusion}

Rezultati analiza broja iglica po dužnom $\mathrm{cm}$, zatim dužina i širina iglica pokazali su postojanje statistički značajnih razlika. Najveći broj iglica po $\mathrm{cm}$ dužnom imala je provenijencija Konjic (16,48 komada), a najmanji broj provenijencija Fojnica (14,52 komada). Najduže iglice je imala provenijencija Fojnica $(19,15 \mathrm{~mm})$, a najkraće provenijencija Prozor $(17,31 \mathrm{~mm})$. Najšire je iglice imala provenijencija Pale $(1,99 \mathrm{~mm})$ a najuže provenijencija Sokolac $(1,89 \mathrm{~mm})$.

Najveća procentualna učešća najstarijih iglica $(5,6,7$ i 8 godina starosti) su imale provenijencije Fojnica i Bosanski Petrovac, dok su najmanje učešće najstarijih iglica imale provenijencije Bugojno i Pale. Za razliku od njih, procentualno najmanje učešće najmlađih iglica (1, 2, i 3 godine starosti), imaju provenijencije Bosanski Petrovac i Fojnica, a najveće provenijencije Bugojno, Pale i Sokolac.

$\mathrm{Na}$ temelju rečenog može se zaključiti da postoje razlike među populacijama iz različitih ekoloških niša, odnosno da razlike u ekologiji staništa uvjetuju morfološku diferencijaciju ispitivanih parametara među populacijama.

Kako sva svojstva pokazuju statistički značajnu razliku, mogu da posluže u poslovima procjene međupopulacijske varijabilnosti u novim istraživanjima.

\section{Literatura - Literature}

BALLIAN, D. (2003): Procjena genetičke varijabilnosti obične jele (Abies alba Mill.) analizom izoenzima u dijelu prirodnih populacija Bosne i Hercegovine i Hrvatske, Šumarski list, br. 3-4: 135-151, Zagreb.

Ballian, D. (2003): Procjena genetičke varijabilnosti obične jele (Abies alba Mill.) analizom cpDNA u dijelu prirodnih populacija Bosne i Hercegovine i Hrvatske, Šumarski list, br. 7-8: 347-357, Zagreb.

BALLIAN, D., ČABARAVDIĆ, A. (2005): Međupopulacijska varijabilnost nekih morfoloških svojstava obične jele (Abies alba Mill.) iz središnje Bosne. Radovi Šumarskog instituta 40 (1): 5-18, Jastrebarsko.

BECKER, A. (1971): Ökologische Varianz der Weisstanne und waldbauliche Folgerungen. Allg. Forstztg., 26 (49): 1011.

BRINAR, M. (1976): Fir seed viability in relation to provenance sites and climate, with respect to fir dieback, Zbornik gozdarstva in lesarstva, 14 (2): 155-190, Ljubljana.

Commarmot, B. (1992): Internationaler Weißtanne-Herkunftsversuch in der Schweiz. 6 IUFRO Tannensymposium, 79-90, Zagreb. 
ĐikIĆ, S., JovanČEVIĆ, M., PANOV, A. (1965): Principi i perspektive unapređenja proizvodnje šumskog sjemena i Bosni i Hercegovini. Šumarski fakultet i Institut za šumarstvo, Posebna izdanja: br.3, str 78, Sarajevo.

FUKAREK, P. (1970): Areali rasprostranjenosti bukve, jele i smrče na području Bosne i Hercegovine. Akademija nauka i umjetnosti BiH, Radovi XXIX, knjiga 11: 231 - 256, Sarajevo.

KAJBA, D. (2001): Unutarpopulacijska i međupopulacijska varijabilnost obične jele. Obična jela u Hrvatskoj, 322-345, Zagreb.

KRAmeR, W., Stephan, B. R. (1992): Zur Entwicklung von Herkünften der Weißtanne (Abies alba Mill.) in Nordwestdeutschland, 6 IUFRO Tannensymposium, Zagreb, 1523, Zagreb.

LARSEN J. B., MEKIĆ, F. (1991): The geographic variation in European silver fir (Abies $a l b a$ ) gas exchange and needle cast in relation to needle age, growth rate dry matter partitioning and wood density by 15 different-provenances at age 6, Silvae Genetica, 40(5-6): 118-198.

MEKIĆ, F. (1988): Gaswechselphysiologische und morfologische Untersuchungen an 5 - 6 jaehrigen Weisstannen-Provenienze (Abies alba Mill.). Dissertation, Institut für Waldbau der Univerzität Göttingen, 1-144. Göttingen.

MEKIĆ, F. (1991): Morfološke karakteristike petogodišnjih sadnica jele (Abies alba Mill.) sa devet lokaliteta u BiH. Univerzitet u Beogradu, Glasnik Šumarskog fakulteta, br. 73 str. $141-152$, Beograd.

MILANOVIĆ, S., MEĐedović, S., KopRIVICA, M. (1980): Uticaj načina sadnje i mineralne ishrane ne neke morfofiziološke osobine jele (Abies alba Mill.), duglazije (Pseudotsuga taxifolia var, viridis.) i bijelog bora (Pinus silvestris L.) u kulturi „Vis“ kod Tarčina. Radovi Šumarskog fakulteta i Instituta za Šumarstvo u Sarajevu, 1-60, Sarajevo.

POPNIKOLA, N. (1974): Proučavanje morfološko-fizioloških karakteristika polena jele (Abies alba Mill.) u vezi sa njenom hibridizacijom. Šumarski list, 95 (9-10): 291-308, Zagreb.

Ruetz, W. F., Franke, A., Stimm, B. (1998): Der Süddeutsche Weißtannen (Abies alba Mill.) Provenienzversuch, Jungendentwicklung auf den Versuchsflächen. Allg. Fors. Und J. Ztg., 169 (6/7): 116-126.

Stefanović, V., Beus, V., BuRlica, Č., DizdareVić, H., Vukorep, I. (1983): Ekološkovegetacijska rejonizacija Bosne i Hercegovine. Šmarski fakultet Univerziteta u Sarajevu, Posebna izdanja: br.17, 1-51, Sarajevo.

UsčUPLIĆ, M. (1992): Uticaj sistema gazdovanja na pojavu imele (Viscum album L.). Glasnik Šumarskog fakulteta u Beogradu, 7-18, Beograd. 
Usčuplić, M., Dautbašıć, M., Treštić, T., Selman, E., Mujezinović, O., Nišıć, T., JokAnović, J. (2007): Bolesti i štetnici obične jele (Abies alba Mill.) u Bosni i Hercegovini. Društvo za zaštitu bilja u BiH, 115, Sarajevo.

VIDAKOVIĆ, M., KRSTINIĆ, A. (1985): Genetika i oplemenjivanje šumskog drveta. Šumarski fakultet, Sveučilište u Zagrebu.

\section{Summary}

On the "Delimusa" section 86, economic units "Krivaja" the SPP "Olovsko", was built experimental plane regular fir with nine provenience. We analyzed the number of needles per $\mathrm{cm}$ by provenience, the length and width of needles by provenience and the participation of needles according to age. The results of the number of needles per $\mathrm{cm}$ and the length and breadth of needles showed the existence of statistically significant difference.

The largest number of needles per $\mathrm{cm}$ had the provenience Konjic (16.48 pieces), and the smallest number of provenience Fojnica (14.52 pieces), while the longest needles had provenience Fojnica $(19.15 \mathrm{~mm})$, and the shortest provenience Prozor $(17,31 \mathrm{~mm})$, to needle-width results showed that the broadest needles had provenience Pale $(1.99 \mathrm{~mm})$, while the needles had close provenience Sokolac (1.89 $\mathrm{mm})$. For all the properties we get statistically significant differences.

The largest percentage of participation oldest needles $(5,6,7$ and 8 years old) had a provenience Fojnica and Bosanska Petrovac, while the minimum participation of the oldest needles provenience had Bugojno and Pale. In contrast, the minimum percentage of participation will be on needles (1,2, and 3 years old), have a provenience Bosanski Petrovac and Fojnica, while the largest participation will be on needles have the provenance of Bugojno, Pale and Sokolac. A foundation can be said that there are differences among populations from different ecological niche, or to differences in the ecology of the habitat influence on the morphologic differentiation measured parameters among populations.

How all the properties show statistically significant difference, that could serve in the affairs estimates among the population variability in the new research. 